\title{
ERRATUM
}

\section{Powder Diffraction Volume 28 / Supplement 2 / September 2013- ERRATUM}

Published by International Center for Diffraction Data with Cambridge University Press, 11 November 2013.

In Powder Diffraction 28(S2) there are several inaccuracies in the footers and headers of the issue. Corrections appear below.

The footers, which currently read Vol. 28, No. S2, September 2013, should read Powder Diffr., Vol. 28, No.S2, September 2013.

The copyright statement, (c) 2013 International Centre for Diffraction Data, should appear at the end of each abstract.

The header of each article should appear as "Technical Article."

The publisher regrets the mistakes.

\section{Reference}

1. EPDIC Proceedings. Powder Diffraction 28(S2), S1-S518 (2013).

(c) International Centre for Diffraction Data. [doi: 10.1017/S0885715614000086] 